\title{
An Investigation on Public Perceptions and Adoption Attitudes towards Electric Vehicles and the Roles of Government Policies in Beijing
}

\author{
L. Li, Y. Gu \\ School of Economics and Management \\ Beijing Information Science \$ Technology University \\ Beijing, China
}

\author{
J.J. Wang \\ School of Economics and Management \\ North China Electric Power University \\ Beijing, China
}

\begin{abstract}
Recent years, because of ever-fast expanding in the consumption of fossil fuel, the air quality gets increasingly bad in Beijing. In order to reduce air pollutants and improve the public living environment, the electric vehicles (EVs) were introduced and encouraged to be adopted by the public, coupled with a series of governmental incentive policies. However, the actual effects of these policies are vague. A survey was designed and conducted to investigate this problem. The survey was designed mainly to answer the following 3 questions: 1) public perceptions of EVs and related policies; 2) public adoption attitudes towards EVs and the roles of governmental policies. Total 434 valid internet responses was received, and the results show that people in Beijing believe that popularizing the EVs can effectively improve the air quality. Although most of the people are not very familiar with EVs, they say they know something In regarding to the adoption attitudes towards EVs, more than half of the ones who plan to buy a new car say they want to buy an EV, that mainly because of the environmental wellness of driving an EV. The effects of the governmental policies on increasing the private adoption willingness of an $\mathrm{EV}$ depend on what value can the $\mathrm{EV}$ bring to them. Suggestions for the future governmental policies for effectively promoting the public adoption of EVs are provided include reinforcing the public perceptions of EVs, constructing more charging facilities for EVs and investing in the research and development of domestic EVs' technologies.
\end{abstract} Beijing

Keywords-perceptions; purchasing attitudes; EVs; policies;

\section{INTRODUCTION}

Beijing is suffering from serious air pollution and urban crowding now. As it is estimated, the automobile exhaust is a major source of air pollutant emissions, accounting for nearly $22 \%$ of the total PM2.5 emissions. Beijing Municipal Environmental Protection Bureau published the < Air Cleaning Plan during 2013-2017 in Beijing > on September 2, 2013, which pointed out that the number of conventional fuel vehicles will be controlled and new energy vehicles including EVs will be increased to about 200,000, with about $70 \%$ private adoption. It is believed that the government will enact several policies to stimulate more people to purchase electric vehicles in Beijing. Actually, the stimulating policies like providing financial subsidies for privates who buy an EV had been implemented for several years, and on January 1th, 2014 an independent vehicle registrations via a lottery system (VRVLS) for alternative fuel vehicles (AFVs) had also been set up. However, the public adoption willingness of EVs seems not increase as much as the policy-makers anticipated.

As it is pointed out, barriers to public widespread adoption of EVs cover every aspect, which can be explained by consumer theory in marketing [1]. Generally speaking, the factors influence the consumers' buying attitudes toward a product mainly includes social, economic, personal lifestyle, beliefs and attitudes, and so on, and this is also the truth for EVs. For example, Diamond [2], Oliver [3], Lane [4] and Carley [5] pointed out the possible perceived risk is one of the most important reasons for public unwilling to buy EVs. Some other researchers found that the perceived economic benefits was also an important factor influence the public adoption attitudes towards EVs. In this regards, because the economic benefits of EVs are determined by the initial purchasing costs, extra battery costs, and saved increasing gasoline consuming costs[6,7], the government financial incentives and increase in gas prices are the main factors forcing public to adopt EVs [8]. Still other researchers found that the personal attitude toward importance of environmental protection is also a vital factor influencing the privates' acceptance of EVs. Kahn [9]found that environmentalists are more likely to purchase HEVs compared to non-environmentalists, and this phenomenon was explained by Heffner [10] in that the environmentalists always choose an EV to symbolize ideas related to one's individuality. Similarly, Gallagher and Muehlegger [11]also found that social preferences for environmental quality and energy security were a major determinant for consumer adoption ofHEVs.

The above researches show that any private decision to buy an EV is finally determined by the value of this behavior can bring them [12], the early adopters many mainly concern about the green-belief value of EVs [13-14], and the common vehicle purchaser requires tangible private value in return. A necessary step toward mass public adoption of PEVs may therefore begin with an accurate public perception of the EVs and related policies, so that they can effectively evaluate the costs and benefits of purchasing and using an EV.

So in this work we want to examine the public perceptions of EVs and related policies in Beijing, and then we want to understand the new car buyers' purchasing preferences toward EVs and the role of government policies. A survey was conducted in order to answer these questions. The rest of this paper is constructed as: section 2 briefly introduces the 
government policies for stimulating the public adoption of EVs, and section 3 presents the survey methods, and the section 4 demonstrates the survey results and the section 5 summarizes the paper and presents advices for future policies' making.

\section{POlicies For Stimulating THE PUblic AdOPTION OF} EVs

\section{A. Financial Incentives}

Of the various AFV technologies in China, EV has gained the most attention lately, and at the beginningof2009, the General Office of the State Council is sued the 'Plan onShapingandRevitalizingtheAutoIndustry', whichsetsoutapro ductiontargetof 500thousandEVs(including PEV, HEV, and Plug-in Hybrid Electric Vehicles (PHEV))anda5\%AFVshareofallvehiclesalesbetween

2009and2012. A "National Energy-Conservation and Alternative Fuel Vehicle Demonstration Program"' was proposed in this plan and one of the major activities was demonstratin genergy-conservation strategies and AFVs (mainly EVs)in medium-and large-size cities. In order to realize the target set by this plan, the MOF,MOST,MIIT and NDRC jointly issued the notice on "pilot providing subsides for the private purchasing of AFV" On May 31, 2010, which pointed out that the privates who decide to purchase an EV can obtain up to 60,000 Yuan RMB of central government financial subsidy.

Beijing was selected as one of the 13 demonstrating cities and in October, 2012, a document named "Beijing pilot passenger cars management approach for private purchasing pure EVs” was draft for receiving comments, which suggested that the privates will also receive up to 60,000 Yuan RMB of Beijing municipal financial subsidy for purchasing pure EVs. So currently, the privates in Beijing who want to purchase an EV can only receive up to 120,000 Yuan RMB of financial subsidy from the central government and local government.

\section{B. Independent VRVLS}

The Beijing government enacted the passenger cars' quota management policy at the end of 2010 and put into practice since Jan 1, 2011. Any individuals who want to buy a passenger car should firstly register and submit the proposal for a car quota in the Beijing passenger cars regulation information system and then the system works like a lottery system to decide who will receive the car quota. Only at the time that the individual receive a car quota, then he can buy a car with Beijing license.

In 2014, Beijing implemented even more strict regulation on the number of new passenger cars and the total number of the car quotas will be reduced to 150, 000 every year. An independent vehicle registration via a lottery system with 20,000 quotas for AFVs opened to the public, while the number of AFVs quota will increase gradually to 60,000 by the end of 2017. As it is restricted, people who applied for AFVs quota should abandon their proposals for conventional car quota. The independent vehicle registration via a lottery system for AFVs is designed to encourage more people to buy EVs. The private probability of receiving an AFV car quota is rather higher than the conventional car quota.

\section{SURVEY}

An internet-based survey was developed and used in this research to collect data from a random selected population. The survey was divided into two parts: the first part was designed to collect information about public perceptions of EVs and related policies, and the second part was to research the EVs' purchasing attitudes of people who plan to buy a new car and the roles of governmental policies. Total 457 responses were received and finally we used 434 valid responses for further analysis. The method used to calculate the sampling error of this survey is [15]

$$
\pm \text { Sample Error }=1.96 * \sqrt{\frac{p(1-p)}{n}}
$$

where $p$ is investigating result of the researching variable, and can be set as 0.5 under the uncertainty conditions, and $n$ is the sample size.

The calculation result shows that the sample error of this survey is $2.4 \%$, which is far less than $5 \%$, so the results of this survey can represent the actual situation of the population.

\section{RESULTS AND ANALYSIS}

\section{A. Public Perceptions of the EVs and Related Policies}

(1) Public perceptions on the importance of popularizing the EVs

The public perceptions toward the air pollution in Beijing were firstly investigated and it implies most people are very dissatisfied with the current air quality in Beijing, more than half of the population feel the air quality is extremely bad, nearly $40 \%$ of the people feel the quality is very bad, while no one feel it is good. At the same time, more than $80 \%$ of them believe that the bad air quality is mainly contributed by the automobile exhaust gases. As a result, most of the people think that popularizing the EVs is a very useful way to improve the air quality in Beijing.

\section{(2) Public knowledge of EVs and financial subsidy policy}

The survey investigates the public knowledge of EVs and related policy by asking questions with isometric scale options. The results show that peoples' knowledge with the EVs and EVs financial purchasing subsidy policy is in the middle level, which is neither too high nor too low, that means although people in Beijing are not very familiar with the EVs, they get some knowledge of the EVs, this is a good start for popularizing the EVs in the future. The same findings show in the knowledge of EVs' financial subsidy policies. However, the overall knowledge level is not so high, the government and related agencies should make great effort to inform the public about the EVs and related policies.

\section{B. Public Buying Attitudes toward EVs and the Role of \\ Related Policies}

In this survey, we investigate peoples' buying plans of new cars in the near future by asking them "Q6: Do you plan to buy a new car in the near future" and the results show that 154 of the sampling population plan to buy a new car (35.48\%). In regarding to the types of buying plan, the survey divided them into five types as, Type A: replacing an old car with Beijing 
license by a new car; Type B: receiving a new car's quota from the VRVLS with Beijing license; Type C: buying a new car with other province's license; Type D: queening for a new car's quota from the VRVLS with Beijing license; Type E: others.

The results of the research show that the buying plans of most of the planners belong to type D (Fig.1), which means at least half of cars' buying wants can't turn into real demand because of the VRVLS policy. The survey investigates their transferring willingness by asking them by "Q7: Do you want to transfer your application for a car quota from the conventional vehicle to AFV?'The results show that 37 of the planners say they want (46.25\%), while 43 of them say they don't want $(53.75 \%)$. The main reason is that they want to make contribution to improving air quality in Beijing or they feel that it is hopeless to get a conventional car quota. The supplement of governmental incentive policies is not the main reason for them to choose an $\mathrm{AFV}$.

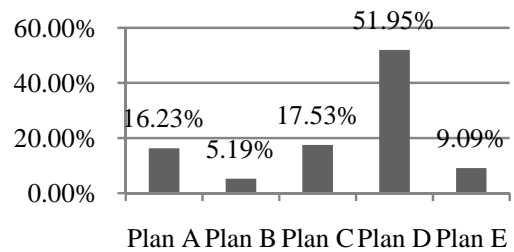

FIGURE I. TYPES OF NEW CARS’ BUYING PLANS

The survey also investigates EV's buying willingness of the ones with Type A, Type B, Type C and Type E buying plans. The results show that 50 of them say that they want to buy an EV (67.57\%) and 24 of them don't want to buy an EV (32.43\%). The main reason for the ones who want to buy an $\mathrm{EV}$ is that they believe an EV can satisfy their basic needs, and only less than $1 / 3$ of the respondents express that the governmental subsidy is the main reason for them to choose an EV. The main reason for the ones who don't want to buy an $\mathrm{EV}$ is that they don't know too much about the EVs.

Combing all of the five car buying plan types, it can be seen that 87 out of 154 respondents show positive willingness to buy an EV (56.49\%), and other 67 respondents show negative willingness to buy an EV (43.51\%).For most of the ones who want to buy an EV, make contribution to the improvement of air quality in Beijing is the dominate reason. For most of the planners with plan $\mathrm{D}$, the chance to be allocated a car' quota licensed by the Beijing municipal government is most valuable for them because they need a car to be used freely inside the city, so they choose to apply for an EV' quota to increase the probability of that chance. Obviously, how many subsidies the governmental provided is not as valuable as the increase in the chance for the planners with plan $\mathrm{D}$, so for these people, the policy of setting up an independent VRVLS is more effective than the governmental subsidy policy. However, for other planners, since they already have the car license of Beijing municipal government, what can the EVs satisfy them is most valuable for them. Besides, the governmental subsidy is more valuable for them than the planners with plan type $\mathrm{D}$, while the importance is still not as much as the basic needs that an EV can satisfy them. No matter what types of new-car buying plan the planners belong to, the common value that driving an EV can improve the air quality in Beijing is attached importance by most of the planners.

\section{CONCLUSIONS AND POLICIES SUGgestions}

\section{A. Conclusions}

(1) Most of the people feel very dissatisfied with the current air quality in Beijing, and they agree that to popularize EVs can effectively improve the air quality in Beijing. People in Beijing are not very familiar with EVs, the same findings on EVs' policies. The one who has an experience of driving an EV feel satisfied with the EVs.

(2) In regarding to current buying attitudes towards EVs, more than half of the people who want to buy a new car show the positive willingness to buy an EV. The environmental benefit ranks the top important factor that drives people to choose an EV. The effects of the governmental subsidy policy and independent VRVLS are different for different groups of new-car buying planners depending on how much value these policies bring to them.

\section{B. Policies Suggestions}

(1) Reinforce the public perceptions of EVs. The government should take plans to provide the public more information about EVs including the performance, environmental effects and technologies development, so as to make people be more familiar with the EVs.

(2) Construct more charging facilities for EVs. Since the public adoption attitude toward EVs is very optimism in Beijing, so what the government should do is to facilitate their usage of EVs. The current charging facilities in Beijing is very scare, the government should take more effects to directly invest or encourage other departments to invest on the charging facilities.

\section{ACKNOWLEDGEMENTS}

This work is financially supported by National Natural Science Foundation of China (71374040, 71373030), Beijing Philosophy and Social Science "Twelfth five" planning project (13JGC074), Collaborative Innovation Center of the Beijing World Urban cycle economy (industry).

\section{REFERENCES}

[1] Rachel M.Krause, SanyaR.Carley, BradleyW.Lane, JohnD.Graham. 2013. Perceptionandreality:Publicknowledgeofplug-inelectricvehiclesin 21U.S.cities, vol. 63, pp. 433-440

[2] Diamond, D., 2009. The impact of government incentives for hybridelectric vehicles: evidence from U.S. states. Energy Policy, vol. 37, 972983

[3] Oliver, J.D., Rosen, D.E., 2010. Applying the environmental propensity framework: a segmented approach to hybrid electric vehicle marketing strategies. The Journal of Marketing Theory and Practice, vol. 18, 377393

[4] Lane, B., Potter, S., 2007. The adoption of cleaner vehicles in the UK: exploring the consumer attitude-action gap. Journal of Cleaner Production, vol.15 , pp. 1085-1092

[5] Carley,S.,Krause,R.M.,Lane,B.W.,Graham,J.D.2013.Intenttopurchaseapl ug-in electric vehicle:asurveyofearlyimpressionsinlargeUScites.TransportationResearc hPartD:TransportandEnvironment,vol.18, pp.39-45

[6] Duvall, M., 2002.Comparing the Benefits and Impacts of Hybrid 
Electric Vehicle Options for Compact Sedan and Sport Utility Vehicles. Electric Power Research Institute, Final Report.

[7] Van Bree, B., Verbong, G.P.J., Kramer, G.J., 2010. A multi-level perspective on the introduction of hydrogen and battery-electric vehicles. Technological Fore- casting and Social Change, vol.77,pp. 529-540

[8] Gallagher, K.S., Muehlegger, E.J., 2011. Giving green to get green? incentives and consumer adoption of hybrid vehicle technology. Journal of Environmental Economics and Management 61, vol.1, pp.1-15

[9] Kahn, M.E., 2007. Do greens drive Hummers or hybrids? Environmental ideology as a determinant of consumer choice. Journal of Environmental Economics and Management, vol. 54, pp.129-145

[10] Heffner, R., Kurani, K.S., Turrentine, T.S., 2007. Symbolism in California's early market for hybrid electric vehicles. Transportation Research Part, vol. 12, pp.396-413.

[11] Gallagher, K.S., Muehlegger, E.J., 2011. Giving green to get green? incentives and consumer adoption of hybrid vehicle technology. Journal of Environmental Economics and Management, vol. 61,pp. 1-15

[12] Hoogma,

R.,Weber,M.,1998.Beyondnationalandtechnologicalstylesofinnovation diffusion:dynamicperspectiveoncasesfromtheenergyandtransport sectors. TechnologyAnalysisandStrategicManagement, vol.10, pp.545-566

[13] Ozaki,

R.,Sevastyanova,K.,2011.Goinghybrid:Ananalysisofconsumerpurchasem otivations.EnergyPolicy, vol.39, pp.2217-2227

[14] Turrentine,T.S.,Kurani,K.S.,2007.Carbuyersandfueleconomy?EnergyPol icy, vol. 35, pp. 1213-1223

[15] Alvin C. Burns, Ronald F. Bush Urns, 2012. Basic Marketing Research: Using Microsoft ${ }^{\circledR}$ ExcelData Analysis, Pearson Education, Inc. 